\title{
Remnant preservation technique versus standard technique for anterior cruciate ligament reconstruction: a meta-analysis of randomized controlled trials
}

\author{
Hong-De Wang ${ }^{1,3}$, Fu-Shun Wang ${ }^{2}$, Shi-Jun Gao ${ }^{1,3}$ and Ying-Ze Zhang ${ }^{1,3,4^{*}}$
}

\begin{abstract}
Background: This meta-analysis was performed to compare the clinical outcomes of primary anterior cruciate ligament $(\mathrm{ACL})$ reconstruction using the $\mathrm{ACL}$ remnant preservation technique versus the standard technique.

Methods: PubMed, Embase, and the Cochrane Library were searched through December 24, 2017, to identify randomized controlled studies that compared the use of the $\mathrm{ACL}$ remnant preservation technique versus the standard technique for primary ACL reconstruction. Statistical heterogeneity among the trials was evaluated with chi-square and I-square tests. A sensitivity analysis was conducted to explore sources of heterogeneity. Subgroup analysis was performed to identify potential differences according to type of ACL remnant tissue (remnant bundle or remnant fibers).

Results: Seven studies with a combined 412 patients (208 in the remnant preservation technique group and 204 in the standard technique group) were included in the meta-analysis. There was a significant difference between the groups in Lysholm score (mean difference (MD), 2.20; 95\% confidence interval $(C \mathrm{I}), 0.95-3.45 ; P=0.0006)$ and side-to-side difference $(\mathrm{MD},-0.71 ; 95 \% \mathrm{Cl},-0.87$ to $-0.55 ; P<0.01)$. There was no significant difference between the groups in subjective International Knee Documentation Committee (IKDC) score, complications, pivot shift test, Lachman test, or overall IKDC score. Subgroup analysis demonstrated that for primary ACL reconstruction with preservation of remnant fibers, the remnant preservation technique was superior to the standard technique based on Lysholm scores $(P<0.01)$ and side-to-side difference $(P<0.01)$.

Conclusions: Based on the current literature, using the remnant preservation technique showed a better clinical outcome than using the standard technique for patients undergoing primary $A C L$ reconstruction with respect to Lysholm score and side-to-side difference. However, it remains unclear that there is a definite advantage to use the remnant preservation technique compared with the standard technique.
\end{abstract}

Keywords: Anterior cruciate ligament, Reconstruction, Remnant preservation, Meta-analysis

\footnotetext{
* Correspondence: profyzzhang@126.com

'Department of Orthopaedic Surgery, The Third Hospital of Hebei Medical

University, No. 139 Ziqiang Road, Qiaoxi District, Shijiazhuang 050051,

People's Republic of China

${ }^{3}$ Key Laboratory of Biomechanics of Hebei Province, Shijiazhuang 050051,

Hebei, People's Republic of China

Full list of author information is available at the end of the article
}

(c) The Author(s). 2018 Open Access This article is distributed under the terms of the Creative Commons Attribution 4.0 International License (http://creativecommons.org/licenses/by/4.0/), which permits unrestricted use, distribution, and reproduction in any medium, provided you give appropriate credit to the original author(s) and the source, provide a link to the Creative Commons license, and indicate if changes were made. The Creative Commons Public Domain Dedication waiver (http://creativecommons.org/publicdomain/zero/1.0/) applies to the data made available in this article, unless otherwise stated. 


\section{Background}

Anterior cruciate ligament (ACL) injury is one of the most common knee injuries with an annual incidence of 68.6 per 100,000 person-years $[1,2]$. An injured ACL cannot heal naturally and will lead to an increased risk of meniscal injury and osteoarthritis [3-5]. Thus, ACL reconstruction is a conventional surgical technique to restore function to the knee with a ruptured ACL, and excellent clinical outcomes have been reported.

Residual ACL remnants are commonly observed during arthroscopic examination. To identify the ACL attachment, the ACL remnant is debrided clearly during ACL reconstruction using standard techniques. In recent years, the importance of the ACL remnant has been recognized in terms of biomechanical, vascular, and proprioceptive function. Some studies reported that mechanoreceptors that control knee proprioception are located in the inner membrane of the synovium near the tibial attachment of the ACL $[6,7]$. In addition, the ACL remnant tissue has good subsynovial and intrafascicular vascularity [6]. This may accelerate cell repopulation and revascularization in the graft. However, the clinical outcomes remain controversial as to the use of the remnant preservation technique versus the standard technique. Some studies reported good clinical outcomes following remnant preservation [8-10]. Kondo et al. [10] reported that the benefit of the remnant preservation technique can significantly improve postoperative knee stability. Lee et al. [11] reported that patients with a remnant greater than $20 \%$ of the length of the ACL had better proprioceptive function than those with less than $20 \%$ length. Conversely, some authors have reported that there is no significant difference between the two techniques, and even that remnant preservation may increase the risk of certain complications and subsequently affect the functional performance of the knee [12, 13].

Based on the current evidence, the purpose of this meta-analysis of randomized controlled trials (RCTs) on the clinical outcomes following either the remnant preservation or the standard technique of ACL reconstruction was to lead to the appropriate selection of technique to provide the greatest benefit to patients. The clinical outcomes that were assessed included knee functionality, stability, subjective evaluation, and complication rate.

\section{Methods}

This meta-analysis was performed according to the guidelines outlined in the Preferred Reporting Items for Systematic Reviews and Meta-Analyses (PRISMA) statement [14].

\section{Study eligibility}

Two reviewers independently decided which studies to include based on the selection criteria. The inclusion criteria were as follows: (1) the article described a RCT (level of evidence, I or II), (2) only the isolated ACL injury, (3) primary ACL reconstruction was performed, (4) reconstruction was performed with the remnant preservation technique or the standard technique, and (5) the study included clinically relevant subjective and objective outcomes, such as subjective patient evaluation, complications, stability, and function.

The exclusion criteria were as follows: (1) the article described a case-control study, retrospective cohort study, case series, review article, letter to the editor, or technique note, (2) injury to multiple knee ligaments, meniscal injury, and/or cartilage injury requiring surgery, (3) the study included the same patients from the same center undergoing the same technique with different follow-up intervals.

\section{Literature search}

We searched PubMed, Embase, and the Cochrane Library to identify RCTs published from the initial date to 24 December 2017 that compared the remnant preservation technique with the standard technique for primary ACL reconstruction. The title and abstract fields were searched for the following terms in each database: anterior cruciate ligament, remnant, preservation. A manual search was also performed for articles potentially missed by the electronic search. The search history of each database is supplied in Additional file 1, Additional file 2, and Additional file 3.

\section{Study selection and data extraction}

Two reviewers independently decided which studies to include based on the selection criteria. Studies were selected in two levels of screening: screening of the titles and abstracts and screening of the full texts. Disagreement between the reviewers was resolved by consensus or by discussion with the senior author if a consensus could not be reached.

The extracted data were assessed by two independent reviewers who reviewed basic information including first author, publication year, study type, sample size, mean age, sex ratio, graft type, fixation method, mean follow-up, and quality assessment score in standardized forms. The primary outcomes were subjective patient evaluation, including subjective International Knee Documentation Committee (IKDC) score and Lysholm score, and complications. The secondary outcomes were knee stability, including the pivot shift test, Lachman test, and side-to-side difference, and knee function, including overall IKDC score. The side-to-side difference was measured with a KT-1000/2000 arthrometer. The mean and standard deviation were not reported in some studies and were calculated by using statistical formulas if the related data was provided [15]. Disagreements were resolved by discussion among the authors. 


\section{Risk of bias assessment}

Two authors independently graded the methodological quality of each eligible study using the Cochrane Collaboration tool to assess the risk of bias for RCTs [16]. The authors assessed random sequence generation, allocation concealment, blinding of participants and personnel, blinding of outcome assessors, incomplete outcome data, selective outcome reporting, and other bias (baseline balance and funding). All fields were judged as having a low risk of bias, high risk of bias, or unclear risk of bias.

\section{Data analysis}

Data analysis was performed with RevMan (Version 5.3; Copenhagen: The Nordic Cochrane Centre, The Cochrane Collaboration, 2014). A random-effects model was adopted to pool the results. The risk ratio (RR) was used as a summary statistic for dichotomous variables, and the mean difference (MD) was used to analyze continuous variables. Both were reported with 95\% confidence intervals (CIs), and a $P$ value of 0.05 was used as the level of statistical significance. Statistical heterogeneity between trials was evaluated with the chi-square and $I$-square tests $\left(I^{2}: 0-30 \%\right.$ was considered homogeneity, $30-60 \%$ was considered moderated heterogeneity, and $>60 \%$ was considered substantial heterogeneity), with significance set at $P<0.10$. A sensitivity analysis was conducted to explore sources of heterogeneity. We also performed a subgroup analysis to identify potential differences according to the type of ACL remnant tissue (remnant bundle or remnant fibers).

\section{Results}

\section{Characteristics of included studies}

A summary of the study selection process is presented in Fig. 1. Our search identified 415 records. A total of 284 citations were discarded because they were duplicates or did not fit the eligibility criteria. After full-text verification of the remaining 15 articles, seven studies with a combined 412 patients (208 in the remnant preservation technique group and 204 in the standard technique group) were included in the meta-analysis [17-23].

All included studies randomized patients to primary ACL reconstruction using hamstring tendon autografts or allografts. All seven studies used the same fixation

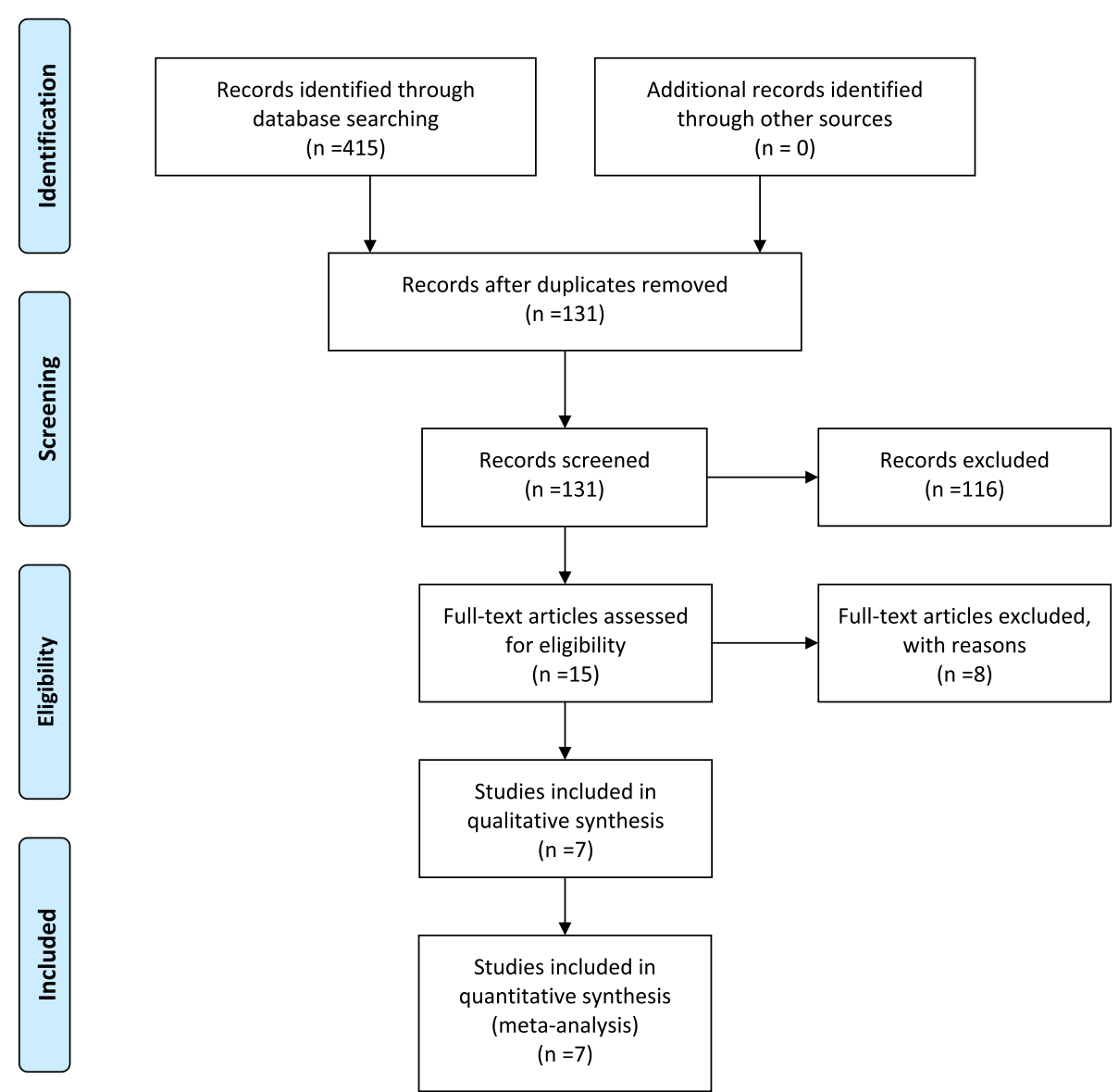

Fig. 1 Selection process for the meta-analysis of studies comparing the ACL remnant preservation technique with the standard technique for $\mathrm{ACL}$ reconstruction 
method for both the remnant preservation technique group and the standard technique group. However, the fixation methods differed between studies. Femoral fixation was obtained with an EndoButton in three studies, RigidFix in two studies, Cross-pin in one study, and Interference screw in one study. Tibial fixation was obtained with a bioabsorbable interference screw in six studies and with an Intrafix in one study. Among the 412 patients, 404 patients used soft-tissue grafts including hamstring tendons and tibialis anterior tendons for ACL reconstruction. Only eight patients used bone-patellar tendon-bone grafts in the study of Pujol et al. Both of the two groups of patients received the same rehabilitation protocols in each included RCT. The characteristics of the included studies are shown in Table 1.

\section{Meta-analysis of clinical outcomes Primary outcomes}

The results of the Lysholm scores (MD, 2.20; 95\% CI, $0.95-3.45 ; P=0.0006)\left(P=0.40\right.$ and $I^{2}=1 \%$ for heterogeneity) showed a statistically significant difference between the remnant preservation technique and the standard technique in favor of the remnant preservation technique. There was no significant difference between the groups in subjective IKDC scores (MD, -0.34 ; 95\% CI, $-2.34-1.67 ; P=0.74)\left(P=0.68\right.$ and $I^{2}=0 \%$ for heterogeneity) or complications (RR, 0.95 ; $95 \% \mathrm{CI}, 0.62-$ 1.46; $P=0.81)\left(P=0.15\right.$ and $I^{2}=41 \%$ for heterogeneity $)$. The results of the primary outcomes are illustrated in Table 2 and Fig. 2. In addition, there was no significant difference between the groups in any individual complication (including revision rate, cyclops lesion or arthrofibrosis) except for impingement (RR, 0.50; 95\% CI, 0.30$0.84 ; P=0.009$ ). The individual complication results are illustrated in Table 3.

\section{Secondary outcomes}

Except for side-to-side difference (MD, $-0.71 ; 95 \% \mathrm{CI}$, $-0.87-0.55 ; P<0.01) \quad\left(P<0.01\right.$ and $I^{2}=91 \%$ for heterogeneity), which was in favor of the remnant preservation technique, there was no significant difference between the remnant preservation technique and the standard technique with respect to secondary stability outcomes, including the pivot shift test and the Lachman test. Moreover, there were no significant differences in secondary functional outcomes on overall IKDC scores. The secondary outcome results are illustrated in Table 2 and Fig. 3.

\section{Sensitivity analysis and subgroup analysis}

Sensitivity analysis was conducted to explore the possibility of heterogeneity in stability outcomes. The results showed that there was no particularly influential study among the included studies, except for the effects of the studies of Andonovski on side-to-side difference [23]. The mean follow-up time in this trial was 7 months. Exclusion of this trial did not alter the results of the side-to-side difference. (MD, $-0.45 ; 95 \% \mathrm{CI},-0.64$ to $0.26 ; P<0.01)\left(P=0.39\right.$ and $I^{2}=0 \%$ for heterogeneity).

Subgroup analysis was performed according to type of remnant tissue (remnant bundle or remnant fibers), as displayed in Table 4. Significant differences were found in both subgroups between the remnant preservation technique and the standard technique in side-to-side difference, and in the subgroup of remnant fibers between the remnant preservation technique and the standard technique in Lysholm scores.

\section{Risk of bias in the included studies}

Information about the risk of bias in each study is presented in Fig. 4. All seven studies had an unclear risk of bias. Random sequence generation was not reported in these seven studies. All of these studies lacked blinding of the participants except for the study by Andonovski. Allocation concealment was carried out adequately in three studies.

\section{Discussion}

This meta-analysis that included seven RCTs suggested that the remnant preservation technique during ACL reconstruction showed a better clinical outcome compared with the standard technique with respect to Lysholm score and side-to-side difference.

Remnant preservation has been recognized to have an important role in ACL reconstruction. However, its actual effectiveness remains controversial. For patients with ACL injury, the first concern is subjective patient evaluation and complications. The differences in subjective evaluation and complications between the use of the remnant preservation technique and the standard technique play an important role in patient choice.

Some previous studies reported that there are mechanoreceptors located in the subsynovial layer near the tibial site of ACL fibers [24, 25]. Moreover, many authors showed that the regeneration of mechanoreceptors may be accelerated by revascularization of the graft and that the recovery of knee proprioceptive function could be promoted by the surviving mechanoreceptors of the ACL remnant and the regenerated mechanoreceptors $[11,25-29]$. Therefore, some authors have preserved the ACL remnant during $\mathrm{ACL}$ reconstruction, assuming that remnant preservation can better restore proprioceptive and functional outcomes of the knee joint [8, 10, 11, 27, 30-32]. Kondo et al. [10] reported that remnant preservation significantly improved postoperative knee stability and arthroscopic evaluation than using the remnant resecting technique during ACL reconstruction. Lee et al. [11] reported in a group of 16 


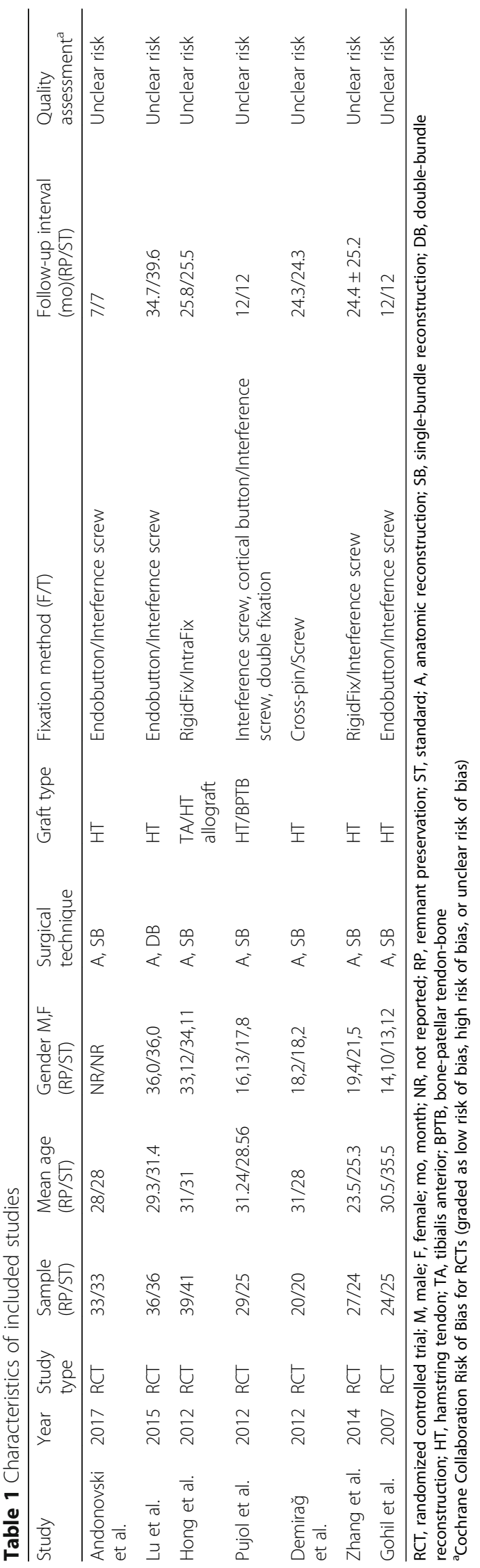


Table 2 Clinical outcomes

\begin{tabular}{|c|c|c|c|c|c|c|}
\hline & $\begin{array}{l}\text { Number of } \\
\text { included studies }\end{array}$ & $\begin{array}{l}\text { Number of } \\
\text { included patients }\end{array}$ & $\mathrm{MD} / \mathrm{RR}$ & $95 \% \mathrm{Cl}$ & $\begin{array}{l}\text { Heterogeneity } \\
\left(P / I^{2}\right)\end{array}$ & $P$ value \\
\hline \multicolumn{7}{|l|}{ Primary outcomes } \\
\hline Subjective IKDC & 3 & 143 & MD -0.34 & {$[-2.34,1.67]$} & $0.68 / 0 \%$ & 0.74 \\
\hline Lysholm score & 5 & 297 & MD 2.20 & {$[0.95,3.45]$} & $0.40 / 1 \%$ & 0.0006 \\
\hline Complications & 5 & 295 & RR 0.95 & {$[0.62,1.46]$} & $0.15 / 41 \%$ & 0.81 \\
\hline \multicolumn{7}{|l|}{ Secondary outcomes } \\
\hline Pivot shift test & 4 & 246 & RR 1.06 & {$[0.97,1.17]$} & $0.80 / 0 \%$ & 0.20 \\
\hline Lachman test & 2 & 120 & RR 1.04 & {$[0.87,1.23]$} & $0.81 / 0 \%$ & 0.69 \\
\hline Side-to-side difference & 4 & 269 & $\mathrm{MD}-0.71$ & {$[-0.87,-0.55]$} & $<0.01 / 91 \%$ & $<0.01$ \\
\hline Overall IKDC & 3 & 206 & RR 1.05 & {$[0.96,1.14]$} & $0.34 / 8 \%$ & 0.27 \\
\hline
\end{tabular}

IKDC, International Knee Documentation Committee

patients that better proprioceptive and functional outcomes occurred in those with a preserved remnant greater than $20 \%$ of the length of the ACL than in those where the remnant was less than 20\%. Yanagisawa et al. [8] reported that the remnant preservation technique reduces the amount of bone tunnel enlargement. Kitamura et al. [32] demonstrated that the preservation of ACL remnant tissue in anatomic double-bundle ACL reconstruction appears to improve the control of pivot-shift laxity at a minimum of 12 months after surgery. However, one study that was included in our analysis demonstrated that remnant preservation had no significant advantage over the standard technique in terms of proprioception function. The other six RCTs included in our analysis did not assess this outcome, so the proprioception between the two techniques cannot be compared. In addition, the proprioceptive function of the knee joint does not depend solely on the ACL. Other factors such as muscles, ligaments, menisci, the joint capsule, and even skin can influence proprioception and make it difficult to directly compare the studies. Therefore, more accurate measurements and clinical outcome scores should be introduced to assess proprioceptive function.

The remnant ACL tissue has good subsynovial and intrafascicular vascularity [6]. Wu et al. [33] reported in an experimental study that blood flow to the grafts was significantly higher in the remnant-preserved group than in the remnant-resected group. Therefore, many authors believed that as the remnant was preserved, a portion of blood vessels from the tibial attachment were also preserved, which may accelerate cell repopulation and

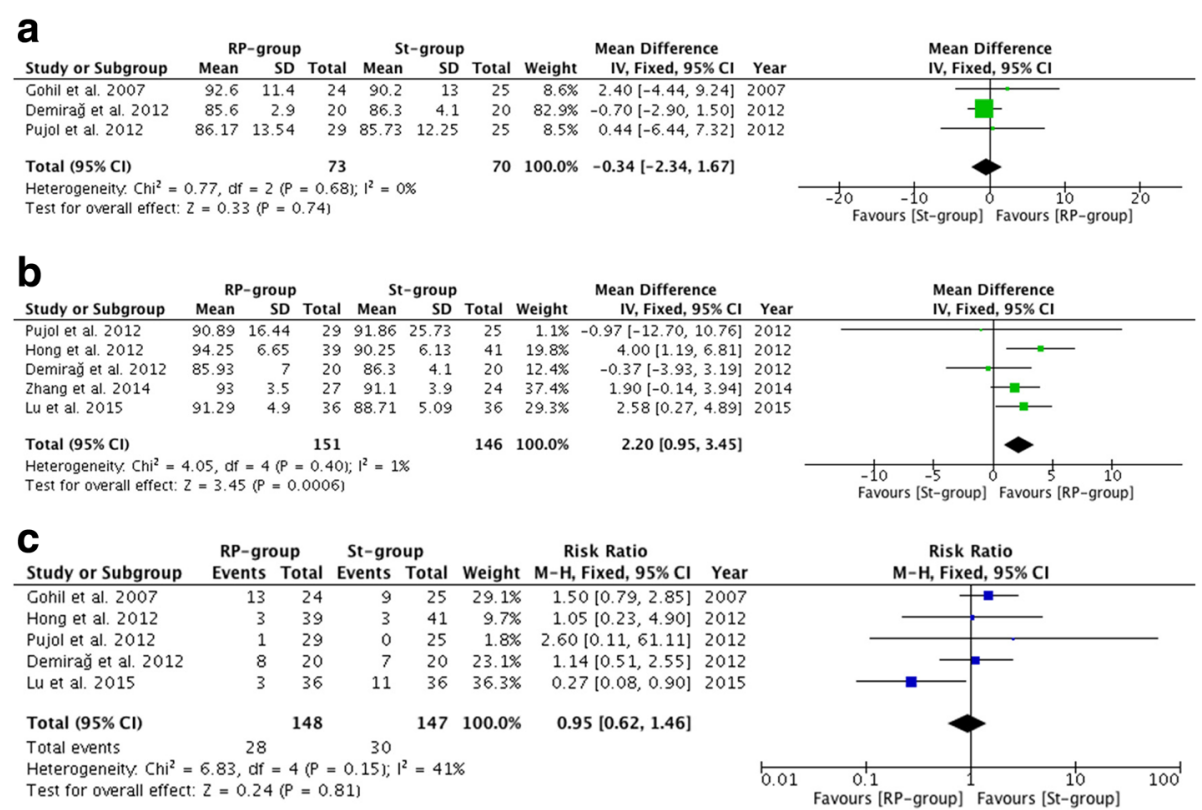

Fig. 2 Primary outcomes after anterior cruciate ligament (ACL) reconstruction. RP-group, Remnant preservation technique group; St-group, Standard technique group. a Subjective International Knee Documentation Committee scores after ACL reconstruction. $\mathbf{b}$ Lysholm scores after ACL reconstruction. c Complications after ACL reconstruction 
Table 3 Complications

\begin{tabular}{lllllll}
\hline & $\begin{array}{l}\text { Number of } \\
\text { included studies }\end{array}$ & $\begin{array}{l}\text { Number of } \\
\text { included patients }\end{array}$ & RR & $95 \% \mathrm{Cl}$ & \multicolumn{2}{c}{$\begin{array}{l}\text { Heterogeneity } \\
\left(P / \mathbb{P}^{2}\right)\end{array}$} \\
\hline Revision & 1 & 72 & 0.20 & {$[0.01,4.03]$} & - & $P$ value \\
Cyclops lesion & 4 & 223 & 1.51 & {$[0.84,2.70]$} & $0.92 / 0 \%$ & 0.29 \\
Arthrofibrosis & 1 & 40 & 1.00 & {$[0.43,2.33]$} & - & 1.00 \\
Impingement & 1 & 72 & 0.50 & {$[0.30,0.84]$} & - & 0.009 \\
\hline
\end{tabular}

revascularization in the graft, resulting in acceleration of graft remodeling and early restoration of the mechanical properties of the graft [34] [35-37]. Ahn et al. [34] reported that magnetic resonance imaging showed significantly larger ACL grafts in the remnant bundle preservation group than in the standard procedure group, and these preserved remnant bundles showed progressive remodeling in the ACL graft. In addition, improved graft remodeling was confirmed by using arthroscopic second-look evaluation [27, 31]. Ahn et al. [27] performed a second-look evaluation in $62 \%$ patients who underwent ACL reconstruction with remnant preservation and reported that $91 \%$ had fair synovialization of the ACL graft. Kondo et al. [10] demonstrated on second-look evaluation that the remnant-preserving procedure was significantly better than the remnant-resecting procedure with regard to postoperative laceration or tear of the grafts as well as synovial and fibrous tissue coverage of the grafts. Two RCTs included in our study reported the second-look evaluation [20, 22]. Lu et al. [22] showed that the grafts in the remnant preservation group had a better quality in terms of synovium coverage, apparent tension, and thickness compared with the standard group. However, Hong et al. [20] observed no significant difference between the two groups on second-look evaluation. Allograft was used in Hong's study, and the follow-up time was 26 months. Previous studies demonstrated that the incorporation of allografts was delayed and that complete remodeling and cellular replacement of the entire graft may require 3 years or longer [38, 39]. This may be a potential cause for

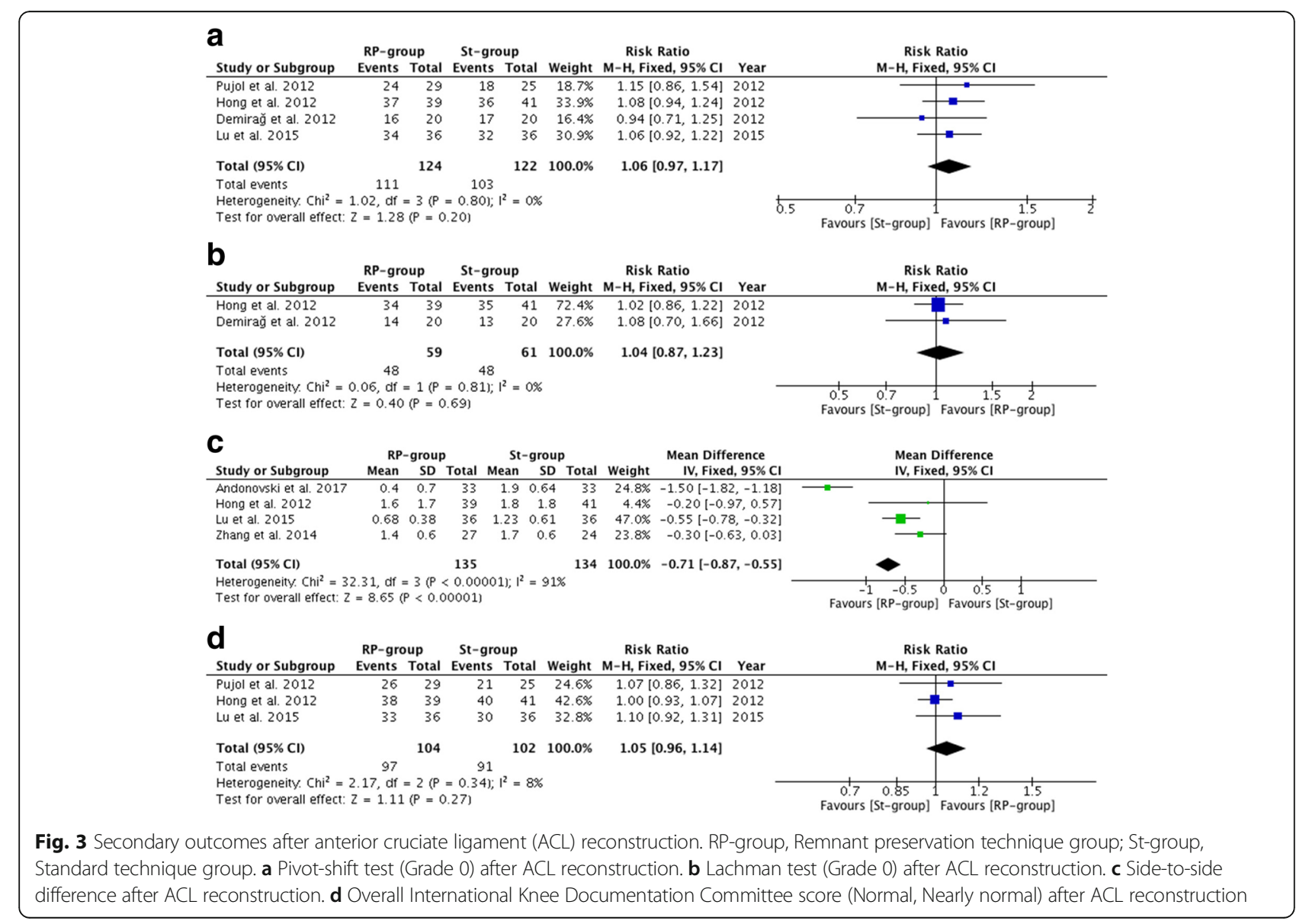


Table 4 Results of subgroup analysis

\begin{tabular}{|c|c|c|c|c|c|c|c|c|}
\hline & \multicolumn{4}{|c|}{ Remnant bundle } & \multicolumn{4}{|c|}{ Remnant fibers } \\
\hline & $\mathrm{MD} / \mathrm{RR}$ & $95 \% \mathrm{Cl}$ & $\begin{array}{l}\text { Heterogeneity } \\
\left(P / R^{2}\right)\end{array}$ & $P$ value & $\mathrm{MD} / \mathrm{RR}$ & $95 \% \mathrm{Cl}$ & $\begin{array}{l}\text { Heterogeneity } \\
\left(P / R^{2}\right)\end{array}$ & $P$ value \\
\hline \multicolumn{9}{|l|}{ Primary outcomes } \\
\hline Subjective IKDC & MD -0.59 & {$[-2.69,1.50]$} & $0.76 / 0 \%$ & 0.58 & MD 2.40 & {$[-4.44,9.24]$} & - & 0.49 \\
\hline Lysholm score & $M D-0.42$ & {$[-3.82,2.98]$} & $0.92 / 0 \%$ & 0.81 & MD 2.61 & {$[1.27,3.96]$} & $0.49 / 0 \%$ & $<0.01$ \\
\hline Complication & RR 1.25 & {$[0.57,2.73]$} & $0.61 / 0 \%$ & 0.58 & RR 0.85 & {$[0.51,1.42]$} & $0.04 / 70 \%$ & 0.54 \\
\hline \multicolumn{9}{|l|}{ Secondary outcomes } \\
\hline Pivot shift test & RR 1.05 & {$[0.85,1.29]$} & $0.34 / 0 \%$ & 0.63 & RR 1.07 & {$[0.97,1.18]$} & $0.87 / 0 \%$ & 0.16 \\
\hline Lachman test & RR 1.08 & {$[0.70,1.66]$} & - & 0.74 & RR 1.02 & {$[0.86,1.22]$} & - & 0.81 \\
\hline Side-to-side difference & $M D-1.50$ & {$[-1.82,-1.18]$} & - & $<0.01$ & $\mathrm{MD}-0.45$ & {$[-0.64,-0.26]$} & $0.39 / 0 \%$ & $<0.01$ \\
\hline Overall IKDC & RR 1.07 & {$[0.86,1.32]$} & - & 0.55 & RR 1.04 & {$[0.96,1.14]$} & $0.28 / 45 \%$ & 0.35 \\
\hline
\end{tabular}

IKDC, International Knee Documentation Committee

increased side-to-side difference especially in the early follow-up. Thus, the graft type (autografts or allografts) and the short follow-up time may have contributed to no significant difference being observed on second-look evaluation between the two groups.

Several studies confirmed that preservation of the remnant during ACL reconstruction can influence the stability of the knee joint, particularly the anterior-posterior stability [27, 30, 40]. Adachi et al. [40] reported that KT-1000 results in remnant-preserved group were $0.7 \pm$ $1.8 \mathrm{~mm}$ versus $1.8 \pm 2.1 \mathrm{~mm}$ in the standard technique group $(P<0.05)$. Kim et al. [11] reported that the postoperative mean side-to-side difference was $1.67 \mathrm{~mm}$ on KT-2000 in patients who underwent double-bundle ACL reconstruction with the remnant-preserved technique. According to our meta-analysis, the side-to-side difference results in both groups were comparable to previous cohort studies. There are likely several reasons why postoperative knee stability was significantly improved by sufficient preservation of the ACL remnant tissue. The biology of graft healing is a process of creeping substitution [36, 37]. The ACL remnant has good subsynovial and intrafascicular vascularity. Therefore, first, the preserved remnant may accelerate the revascularization and ligamentation of the grafts, as well as its incorporation and stability. Second, the present study showed that in remnant-preserved reconstruction, the tibial attachment of the ACL remnant tissue, which appeared to be almost normal, was maintained around the tibial tunnel site. In contrast, Tomita et al. [41] reported that the tibial attachment in the remnant-resected ACL reconstruction was narrow and had a different shape in comparison with the normal attachment. This may explain the finding that the impingement rate was significantly higher in the standard technique group compared with the remnant preservation group $(P=0.009)$.

A potential complication of ACL reconstruction using remnant preservation is cyclops syndrome or a cyclops lesion [28]. The incidence of cyclops syndrome, which involves serious loss of knee extension caused by a hard nodule around the reconstructed ACL, has been reported to range from 2 to $11 \%[42,43]$. The incidence of a cyclops lesion, which is a soft synovial tissue mass without any clinical symptoms around the reconstructed ACL, has been reported to range from 2 to $47 \%$ [27, 42, 44]. Four RCTs included in our meta-analysis reported cyclops lesion occurrence (18 of 112 in the remnant preservation technique group, 12 of 111 in the standard technique group) $[17,19-21]$. Only one patient required arthroscopic arthrolysis for cyclops syndrome [21]. Some magnetic resonance imaging studies showed that there was no significant difference in the prevalence of cyclops lesion after single-bundle ACL reconstruction between the remnant-preserved and remnant-resected techniques (12.2\% and $15.0 \%$, respectively). The results of our meta-analysis showed no significant difference in the occurrence of cyclops lesions between the remnant preservation technique and the standard technique ( $16.1 \%$ and $10.8 \%$, respectively. $P=0.17$ ). Thus, we hypothesized that the preservation of ACL remnant tissue does not increase the incidence of cyclops lesions.

The types of remnant preservation used in the seven RCTs were either remnant bundle preservation or remnant fiber preservation. The former type can be defined as a single-bundle rupture (anteromedial bundle or posterolateral bundle) with the other bundle remnant preserved. The latter type can be defined as a double-bundle rupture with the remnant fiber preserved. According to the results of the subgroup analysis, there were significant differences in terms of side-to-side difference between the subgroup and the standard technique group. This finding suggests that if the remnant tissue is a bundle, surgeons should attempt to preserve the remnant bundle, while if the remnant tissue is only fibers, the remnant fibers should be preserved. Interestingly, there was a significant difference in Lysholm scores between the subgroup of 




b

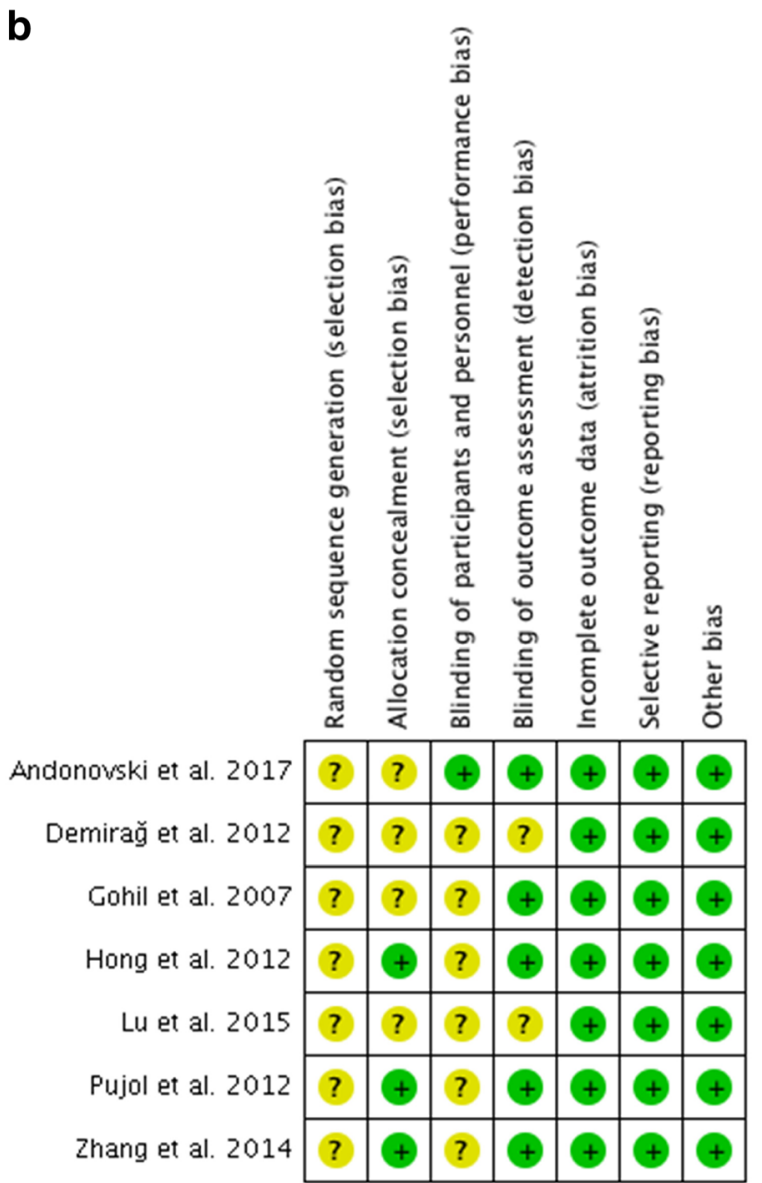

Fig. 4 Risk of bias for each randomized controlled trial (RCT). a Graph depicting risk of bias. $\mathbf{b}$ Summary of risk of bias in the included studies

remnant fiber preservation and the standard technique group in favor of the subgroup.

\section{Limitation}

This study had several limitations. First, all seven studies were rated as having an unclear risk of bias because the method of blinding patients was not reported or blinding was not used. Blinding is rarely possible in surgical studies, which is an inherent limitation of conducting randomized trials. Second, the standard deviation was unavailable in some studies, so the imputed standard deviation was used for pooling of the data. Third, the duration of final follow-up was substantially different among the included studies, ranging from 7 to 49 months, and this difference may have obscured the reporting of differences between the two groups. Finally, the grafts used for ACL reconstruction were not of the same type and included autograft and allograft, which might influence the incorporation between the remnant and graft.

\section{Conclusion}

Based on the current literature, using the remnant preservation technique showed a better clinical outcome than using the standard technique for patients undergoing primary ACL reconstruction with respect to Lysholm score and side-to-side difference. However, it remains unclear that there is a definite advantage to use the remnant preservation technique compared with the standard technique.

\section{Additional files}

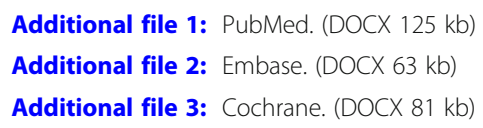

\section{Abbreviations}

ACL: Anterior cruciate ligament; Cls: Confidence intervals; IKDC: International Knee Documentation Committee; MD: Mean difference; PRISMA: Preferred Reporting Items for Systematic Reviews and Meta-Analyses;

RCTs: Randomized controlled trials; RR: Risk ratio

\section{Availability of data and materials}

The data of the manuscript was presented in the paper and supplemental files.

\section{Authors' contributions}

HDW and FSW performed the literature search, screened the potential subject, and extracted and integrated the data independently at the same time; HDW and FSW checked the data; HDW designed the study and drafted the initial manuscript; SJG and YZZ critically revised the manuscript; YZZ provided final approval of the version to be published. All authors read and approved the final manuscript.

\section{Ethics approval and consent to participate}

Not applicable.

\section{Consent for publication \\ Not applicable.}

\section{Competing interests}

The authors declare that they have no competing interests.

\section{Publisher's Note}

Springer Nature remains neutral with regard to jurisdictional claims in published maps and institutional affiliations.

\section{Author details}

'Department of Orthopaedic Surgery, The Third Hospital of Hebei Medical University, No. 139 Ziqiang Road, Qiaoxi District, Shijiazhuang 050051, People's Republic of China. ${ }^{2}$ Department of Orthopaedic Surgery, XinHuaFuShun Clinic of Traditional Chinese and Western Medicine, No. 398 Youyi North Street, Xinhua District, Shijiazhuang 050051, People's Republic of China. ${ }^{3}$ Key Laboratory of Biomechanics of Hebei Province, Shijiazhuang 
050051, Hebei, People's Republic of China. ${ }^{4}$ Chinese Academy of

Engineering, Beijing 100088, People's Republic of China.

Received: 5 June 2018 Accepted: 3 September 2018 Published online: 12 September 2018

\section{References}

1. Shelbourne KD, Gray T, Haro M. Incidence of subsequent injury to either knee within 5 years after anterior cruciate ligament reconstruction with patellar tendon autograft. Am J Sports Med. 2009;37:246-51.

2. Sanders TL, Maradit Kremers H, Bryan AJ, Larson DR, Dahm DL, Levy BA, Stuart MJ, Krych AJ. Incidence of anterior cruciate ligament tears and reconstruction: a 21-year population-based study. Am J Sports Med. 2016; 44:1502-7.

3. Musahl V, Rahnemai-Azar AA, Costello J, Arner JW, Fu FH, Hoshino Y Lopomo N, Samuelsson K, Irrgang JJ. The influence of meniscal and anterolateral capsular injury on knee laxity in patients with anterior cruciate ligament injuries. Am J Sports Med. 2016;44:3126-31.

4. Cimino F, Volk BS, Setter D. Anterior cruciate ligament injury: diagnosis, management, and prevention. Am Fam Physician. 2010;82:917-22.

5. Barenius B, Ponzer S, Shalabi A, Bujak R, Norlen L, Eriksson K. Increased risk of osteoarthritis after anterior cruciate ligament reconstruction: a 14-year follow-up study of a randomized controlled trial. Am J Sports Med. 2014;42: 1049-57.

6. Dhillon MS, Bali K, Vasistha RK. Immunohistological evaluation of proprioceptive potential of the residual stump of injured anterior cruciate ligaments (ACL). Int Orthop. 2010;34:737-41.

7. Bali K, Dhillon MS, Vasistha RK, Kakkar N, Chana R, Prabhakar S. Efficacy of immunohistological methods in detecting functionally viable mechanoreceptors in the remnant stumps of injured anterior cruciate ligaments and its clinical importance. Knee Surg Sports Traumatol Arthrosc. 2012;20:75-80

8. Yanagisawa S, Kimura M, Hagiwara K, Ogoshi A, Nakagawa T, Shiozawa H, Ohsawa T, Chikuda H. The remnant preservation technique reduces the amount of bone tunnel enlargement following anterior cruciate ligament reconstruction. Knee Surg Sports Traumatol Arthrosc. 2018;26(2):491-9.

9. Nakayama H, Kambara S, Iseki T, Kanto R, Kurosaka K, Yoshiya S. Doublebundle anterior cruciate ligament reconstruction with and without remnant preservation - comparison of early postoperative outcomes and complications. Knee. 2017;24:1039-46.

10. Kondo E, Yasuda K, Onodera J, Kawaguchi Y, Kitamura N. Effects of remnant tissue preservation on clinical and arthroscopic results after anatomic double-bundle anterior cruciate ligament reconstruction. Am J Sports Med. 2015;43:1882-92.

11. Lee BI, Kwon SW, Kim JB, Choi HS, Min KD. Comparison of clinical results according to amount of preserved remnant in arthroscopic anterior cruciate ligament reconstruction using quadrupled hamstring graft. Arthroscopy. 2008;24:560-8

12. McMahon PJ, Dettling JR, Yocum LA, Glousman RE. The cyclops lesion: a cause of diminished knee extension after rupture of the anterior cruciate ligament. Arthroscopy. 1999;15:757-61.

13. Tonin M, Saciri V, Veselko M, Rotter A. Progressive loss of knee extension after injury. Cyclops syndrome due to a lesion of the anterior cruciate ligament. Am J Sports Med. 2001;29:545-9.

14. Harris JD, Quatman CE, Manring MM, Siston RA, Flanigan DC. How to write a systematic review. Am J Sports Med. 2014:42:2761-8.

15. Hozo SP, Djulbegovic B, Hozo I. Estimating the mean and variance from the median, range, and the size of a sample. BMC Med Res Methodol. 2005;5:13.

16. Higgins J, Green S. Cochrane handbook for systematic reviews of interventions version 5.1.0 [updated March 2011]. Naunyn-Schmiedeberg's Arch Exp Pathol Pharmakol. 2014;5:S38.

17. Gohil S, Annear PO, Breidahl W. Anterior cruciate ligament reconstruction using autologous double hamstrings: a comparison of standard versus minimal debridement techniques using MRI to assess revascularisation. A randomised prospective study with a one-year follow-up. J Bone Joint Surg Br. 2007;89:1165-71.

18. Zhang Q, Zhang S, Cao X, Liu L, Liu Y, Li R. The effect of remnant preservation on tibial tunnel enlargement in $\mathrm{ACL}$ reconstruction with hamstring autograft: a prospective randomized controlled trial. Knee Surg Sports Traumatol Arthrosc. 2014;22:166-73.
19. Demirağ B, Ermutlu C, Aydemir F, Durak K. A comparison of clinical outcome of augmentation and standard reconstruction techniques for partial anterior cruciate ligament tears. Eklem Hastalik. Cerrahisi [Joint diseases \& related surgery]. 2012;23:140-4.

20. Hong L, Li X, Zhang H, Liu X, Zhang J, Shen JW, Feng H. Anterior cruciate ligament reconstruction with remnant preservation: a prospective, randomized controlled study. Am J Sports Med. 2012;40:2747-55.

21. Pujol N, Colombet P, Potel JF, Cucurulo T, Graveleau N, Hulet C, Panisset JC, Servien E, Sonnery-Cottet B, Trojani C, et al. Anterior cruciate ligament reconstruction in partial tear: selective anteromedial bundle reconstruction conserving the posterolateral remnant versus single-bundle anatomic $\mathrm{ACL}$ reconstruction: preliminary 1-year results of a prospective randomized study. Orthop Traumatol Surg Res. 2012;98:S171-7.

22. Lu W, Wang D, Zhu W, Li D, Ouyang K, Peng L, Feng W, Li H. Placement of double tunnels in $\mathrm{ACL}$ reconstruction using bony landmarks versus existing footprint remnant: a prospective clinical study with 2-year follow-up. Am J Sports Med. 2015:43:1206-14.

23. Andonovski A, Topuzovska S, Samardziski M, Bozinovski Z, Andonovska $B$, Temelkovski Z. The influence of anterior cruciate ligament remnant on postoperative clinical results in patients with remnant preserving anterior cruciate ligament reconstruction. Open Access Maced J Med Sci. 2017;5:624-9.

24. Aydog ST, Korkusuz P, Doral MN, Tetik O, Demirel HA. Decrease in the numbers of mechanoreceptors in rabbit ACL: the effects of ageing. Knee Surg Sports Traumatol Arthrosc. 2006;14:325-9.

25. Lee BI, Min KD, Choi HS, Kwon SW, Chun DI, Yun ES, Lee DW, Jin SY, Yoo JH. Immunohistochemical study of mechanoreceptors in the tibial remnant of the ruptured anterior cruciate ligament in human knees. Knee Surg Sports Traumatol Arthrosc. 2009;17:1095-101.

26. Adachi N, Ochi M, Uchio Y, Iwasa J, Ryoke K, Kuriwaka M. Mechanoreceptors in the anterior cruciate ligament contribute to the joint position sense. Acta Orthop Scand. 2002;73:330-4.

27. Ahn JH, Wang JH, Lee YS, Kim JG, Kang JH, Koh KH. Anterior cruciate ligament reconstruction using remnant preservation and a femoral tensioning technique: clinical and magnetic resonance imaging results. Arthroscopy. 2011;27:1079-89.

28. Georgoulis AD, Pappa L, Moebius U, Malamou-Mitsi V, Pappa S, Papageorgiou CO, Agnantis NJ, Soucacos PN. The presence of proprioceptive mechanoreceptors in the remnants of the ruptured $\mathrm{ACL}$ as a possible source of re-innervation of the ACL autograft. Knee Surg Sports Traumatol Arthrosc. 2001;9:364-8.

29. Ochi M, Adachi N, Uchio Y, Deie M, Kumahashi N, Ishikawa M, Sera S. A minimum 2-year follow-up after selective anteromedial or posterolateral bundle anterior cruciate ligament reconstruction. Arthroscopy. 2009;25:117-22.

30. Kim SJ, Jo SB, Kim TW, Chang JH, Choi HS, Oh KS. A modified arthroscopic anterior cruciate ligament double-bundle reconstruction technique with autogenous quadriceps tendon graft: remnant-preserving technique. Arch Orthop Trauma Surg. 2009;129:403-7.

31. Lee JH, Bae DK, Song SJ, Cho SM, Yoon KH. Comparison of clinical results and second-look arthroscopy findings after arthroscopic anterior cruciate ligament reconstruction using 3 different types of grafts. Arthroscopy. 2010;26:41-9.

32. Kitamura N, Yasuda K, Yokota M, Goto K, Wada S, Onodera J, Kondo E. The effect of intraoperative graft coverage with preserved remnant tissue on the results of the pivot-shift test after anatomic double-bundle anterior cruciate ligament reconstruction: quantitative evaluations with an electromagnetic sensor system. Am J Sports Med. 2017;45:2217-25.

33. Wu B, Zhao Z, Li S, Sun L. Preservation of remnant attachment improves graft healing in a rabbit model of anterior cruciate ligament reconstruction. Arthroscopy. 2013;29:1362-71.

34. Ahn JH, Lee SH, Choi SH, Lim TK. Magnetic resonance imaging evaluation of anterior cruciate ligament reconstruction using quadrupled hamstring tendon autografts: comparison of remnant bundle preservation and standard technique. Am J Sports Med. 2010;38:1768-77.

35. Howell SM, Knox KE, Farley TE, Taylor MA. Revascularization of a human anterior cruciate ligament graft during the first two years of implantation. Am J Sports Med. 1995;23:42-9.

36. Deehan DJ, Cawston TE. The biology of integration of the anterior cruciate ligament. J Bone Joint Surg Br. 2005;87:889-95.

37. Zaffagnini S, De Pasquale V, Marchesini Reggiani L, Russo A, Agati P, Bacchelli B, Marcacci M. Neoligamentization process of BTPB used for ACL graft: histological evaluation from 6 months to 10 years. Knee. 2007;14:87-93. 
38. Malinin TI, Levitt RL, Bashore C, Temple HT, Mnaymneh W. A study of retrieved allografts used to replace anterior cruciate ligaments. Arthroscopy. 2002;18:163-70.

39. Wang HD, Gao SJ, Zhang YZ. Comparison of clinical outcomes after anterior cruciate ligament reconstruction using a hybrid graft versus a hamstring autograft. Arthroscopy. 2018:34(5):1508-16.

40. Adachi N, Ochi M, Uchio Y, Sumen Y. Anterior cruciate ligament augmentation under arthroscopy. A minimum 2-year follow-up in 40 patients. Arch Orthop Trauma Surg. 2000;120:128-33.

41. Tomita F, Yasuda K, Mikami S, Sakai T, Yamazaki S, Tohyama H. Comparisons of intraosseous graft healing between the doubled flexor tendon graft and the bone-patellar tendon-bone graft in anterior cruciate ligament reconstruction. Arthroscopy. 2001;17:461-76.

42. Sonnery-Cottet B, Lavoie F, Ogassawara R, Kasmaoui H, Scussiato RG, Kidder JF, Chambat P. Clinical and operative characteristics of cyclops syndrome after double-bundle anterior cruciate ligament reconstruction. Arthroscopy. 2010;26:1483-8

43. Wang J, Ao Y. Analysis of different kinds of cyclops lesions with or without extension loss. Arthroscopy. 2009;25:626-31.

44. Gohil S, Falconer TM, Breidahl W, Annear PO. Serial MRI and clinical assessment of cyclops lesions. Knee Surg Sports Traumatol Arthrosc. 2014; 22:1090-6.

Ready to submit your research? Choose BMC and benefit from:

- fast, convenient online submission

- thorough peer review by experienced researchers in your field

- rapid publication on acceptance

- support for research data, including large and complex data types

- gold Open Access which fosters wider collaboration and increased citations

- maximum visibility for your research: over $100 \mathrm{M}$ website views per year

At BMC, research is always in progress.

Learn more biomedcentral.com/submissions 